\title{
ELONGATION OF THE ACTIVE ANTERIOR WALL OF THE URO-GENITAL PELVIC DIAPHRAGM, A LATE UNUSUAL COMPLICATION OF PARAPLEGIA
}

\author{
By F. Jurascheck, M.D., P. Dollfus, M.D. and D. Jacob-Chia, M.D. \\ Centre Hôspitalier, 68 Mulhouse, France
}

\begin{abstract}
The situation of the usual bladder, prostate, membranous urethra channel, can vary, according to the morphology of the perineum which can be overstretched. A case of a young man with a Tio complete upper motor neurone lesion is presented. The normal anterior angulation at the prostate and membranous urethra junction was reduced anteriorly and pushed backwards, thus causing an added indirect factor of dysuria. The mechanism is discussed in comparison with other such late, but often overlooked consequences of alterations of the pelvic floor during micturition.
\end{abstract}

Key words: Spinal cord injuries; Neurogenic bladder.

\section{Introduction}

Patients with a lower motor neurone lesion (LMNL), as time passes by, show definite signs of increasing static disturbances of the pelvic floor when voiding. Usually, patients with an upper motor neurone lesion (UMNL) show little, or no displacement, of the proximal urinary tract axis, as it is maintained by a tonic pelvic floor, dysuria being caused usually by a hypertonic external sphincter. Micturition in these patients is usually started by supra-pubic percussion, or other means of triggering the voiding reflex. Other patients with an UMNL attempt to void by raising the intra-abdominal pressure, thus creating with the help of the diaphragm an internal and external 'Credé' manoeuvre. The risk, here, is that the innervated perineum can relax practically in the same way as in a LMNL, dysuria being caused by an insufficient opening of the internal sphincter not taking into account the external sphincter which can act in a dyssynergic way. In LMN lesions, the pelvic floor is distended passively, the combination of back- and down-tilting of the

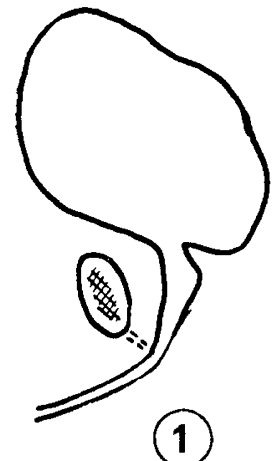

FIG. I

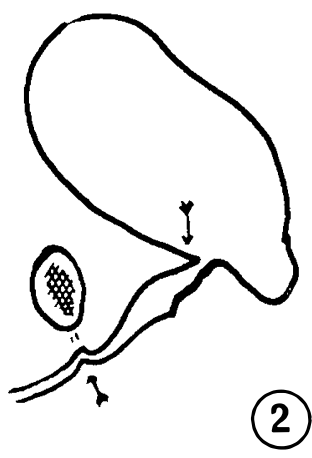

FIG. 2

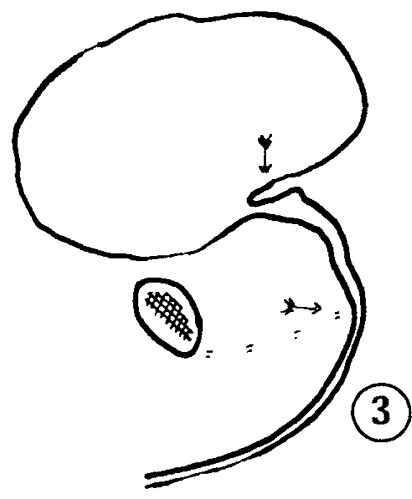

FIG. 3 
bladder base, and posterior wall, pressing on the atonic pelvic floor will displace backwards the resultant of the intravesical forces exerted by the abdominal strain, literally missing the internal sphincter. Furthermore the stretching of the pubovesical ligaments will enhance this phenomenon even more. We have published such a type of obstruction in a LMN lesion (Figs I and 2) (Jurascheck \& Dollfus, 1972). This particular problem was solved by performing a prostato-cystopexy (Fig. 4). Since, three patients, all with LMN lesions and with a similar type of dysuria were operated with success. Another different type of mechanical obstruction was detected in an UMN lesion with a sagging pelvic floor, the prostate, this time, being tilted anteriorly (Fig. 3), causing an anterior prostate-membranous urethra angle. This mechanism can only be understood if one suspects a passive distension (eventually a partial rupture) of the anterior ligaments and/or muscles between the proximal urethra and the pubis.

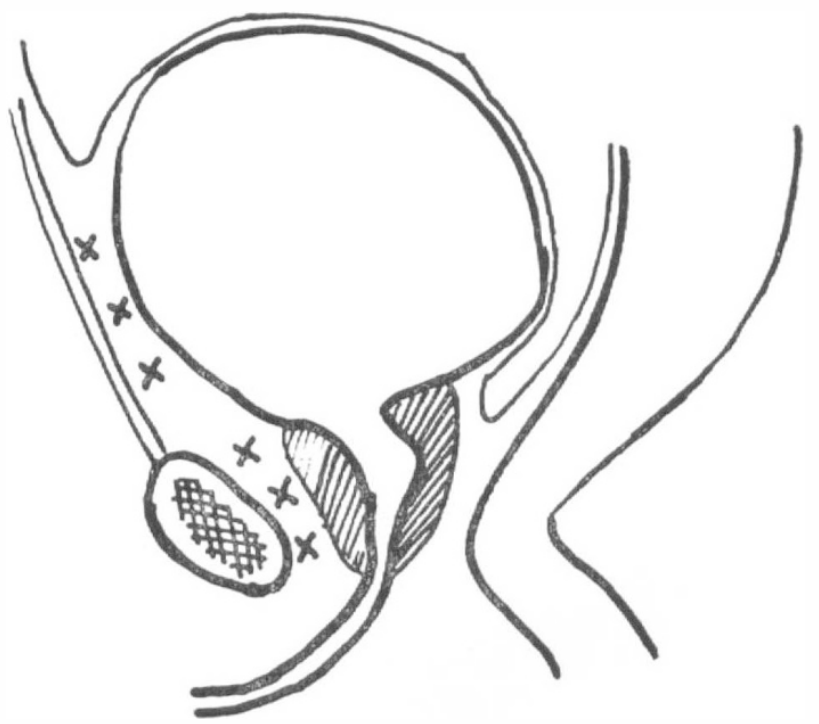

FIG. 4

\section{Case Report}

GIS . . . Alain, 29 years old, when aged I6 sustained, after a fall, a fracture of $\mathrm{T}_{7}$ to $\mathrm{T} 9$ with a complete spinal cord lesion below T8. His case report is, unfortunately, very complex, mainly because of poor management, his paraplegia being discovered four days after injury (!), when he regained consciousness. A cystostomy was performed because of an indwelling catheter retention. A bladder neck resection was performed after the closure of the cystostomy.

He was seen here four years after the accident and a 2 and Io o'clock resection of the external sphincter was performed. At that time, a diverticulum of the urethra was diagnosed. An appendicular abscess of the Douglas recess was operated, and in 1975, the diverticulum, according to a technique described elsewhere (Jurascheck et al., 1978), converting the urethra into a gutter with the concavity superior and the sides sutured to the corpora cavernosa. In 1972 (Fig. 5a) the prostate was in a normal position but in 1978 (Fig. 6a) by the relaxation of its sub-pubic anchoring, it progressively moved backwards and became horizontal, causing a posterior clapper upon the bladder neck.

His actual way of voiding is in a semi-sitting position, after contracting his abdominal wall muscles, pushing as hard as possible in apnoea, nearly achieving at the same time a 'Credé' and a Valsava manoeuvre. An EMG examination of the perineum, during this 


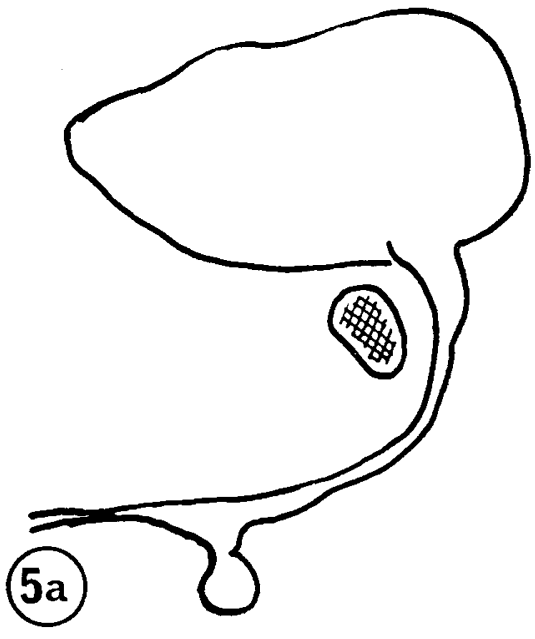

FIG. 5A

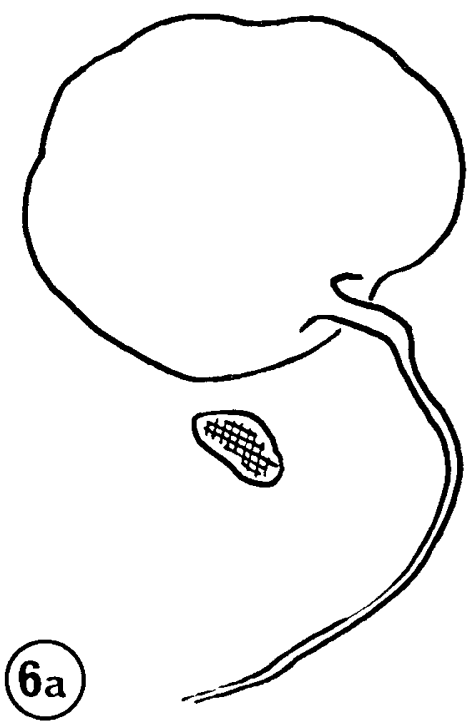

FIG. 6A

manoeuvre, was performed, which showed, while attempting to void, that there was very little electrical activity. On the other hand, while trying to void by supra-pubic percussion, the perineum muscles were electrically very active. His upper urinary tract is actually normal. The urine is sterile, the residual is low, using the first method at the cost of considerable effort. In the second way, residual is also low but voiding takes a much longer time (20 minutes against 5). Actually working, he has chosen the first method, for 'comfort'.

We have presented this case, mainly to demonstrate an unusual mechanical obstruction of the lower urinary tract. Other similar disturbances have been accounted for in the literature (Dollfus et al., I972; Jurascheck et al., 1974; Archimbaud, I974; Madersbacher, 1977) but for LMN lesions only. One must be alerted to these insidious changes and a dynamic urinary check-up must be performed with this type of mechanical dysuria in mind, even in UMNL. Electromyography can be of great diagnostic help, including EMG changes in the anterior and posterior part of the perineum. In this patient, it might be dangerous for him to continue voiding in his actual manner and, if all other attempts fail, we might be tempted to propose a prostato-cystopexy.

\section{RÉSUMÉ}

Une nouvelle forme dysuriante de bascule de la filière vésico-uréthrale est décrite chez un paraplégique. Les auteurs rappellent des cas précédents, déjà décrits, avec une technique de réparation personnelle, mais pour des lésions du neurone périphérique.

\section{ZUSAMMENFASSUNG}

Eine ungewöhnliche Harnstockung bei einem Querschnittgelähmten durch Beugung der Prostata wird beschrieben. Die Autoren beschreiben im Zusammenhang mit früher beschriebenen Fällen den Grund dieser Pathologie. 


\section{REFERENCES}

ARChimbaud, J. P. (1974). Les dysfonctionnements vésico-sphinctériens neurologiques. Rapport à l'Association Française d'Urologie, Ed. Masson \& Cie, Paris.

Bors, E. \& Comarr, A. E. (I97I). Neurological Urology, Ed. Karger, Basle.

CouvelaIRE, R. \& CUKIER, J. (I974). Nouveau traité de technique chirurgicale Tome XV, Urologie, Ed. Masson \& Cie, Paris.

Dollfus, P., JuRAscheck, F., JaCob-Chia, D. \& Peter, E. (1972). Prostato-cystopexy for a paraplegic case with an inactive bladder and perineum, Paraplegia, 10, 64-67.

JuRAsCHeCK, F., Dollfus, P., MenNeCier, A. \& Moustafa, C. (I974). Problèmes posés par les paralysies flasques des muscles du périnée. Rapport au Congrès d'Urologie, 298-302, Ed. Masson \& Cie, Paris.

Jurascheck, F., Dollfus, P., Notter, A., Moustafa, C. \& Mennecier, A. (1978). Le traitement des sténoses urétrales et des lésions en amont des rétrécissements chez les malades présentant une cicatrisation déficiente (paraplégie-tuberculose). Société Française d'Urologie, I4 mai 1977. F. d'Urol. et Néphr., 84, I00-105.

MADERSBACHER, H. (I977). The neuropathic urethra: urethrogram and pathophysiologic aspects. Europ. Urol., 3, 321-332. 